International Journal of Pure and Applied Mathematics

Volume 95 No. 3 2014, 367-385

ISSN: 1311-8080 (printed version); ISSN: 1314-3395 (on-line version)

url: http://www.ijpam.eu

doi: http://dx.doi.org/10.12732/ijpam.v95i3.5

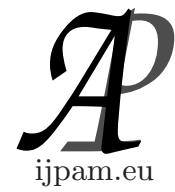

\title{
THE TEMPORAL AND SPATIAL DYNAMICS OF REGIONAL CITY-SIZE DISTRIBUTION: AN INDIAN STATE - KERALA (1951-2001)
}

\author{
V. Christopher Amalraj ${ }^{1 \S}$, A. Subbarayan ${ }^{2}$ \\ ${ }^{1}$ Department of Community Medicine \\ SRM Medical College and Research Centre \\ SRM University \\ Kattankulathur, 603 203, Tamil Nadu, INDIA \\ ${ }^{2}$ Department of Computer Applications \\ SRM University \\ Kattankulathur, 603 203, Tamil Nadu, INDIA
}

\begin{abstract}
This paper aims at evaluating the temporal and spatial dynamics of City Size Distribution in Kerala, an Indian State for the period 1951-2001. The study is based on a function relating population size to rank and the same is used to test for the trends of deconcentration and spatial decentralization. The expansion methodology is used to investigate the dynamics of rank size function in both temporal and spatial dimensions.Our findings reveals that the size distribution of cities/towns in the state shows an increasing and decreasing pattern and indicating a more even and less even distribution cities/towns populations. The study also indicates that distance from a central city is not a significant factor in any trend towards population deconcentration.
\end{abstract}

Key Words: city-size distribution, Paretos law, Zipfs law, rank-size distribution, expansion method, Spatio temporal models

\section{Introduction}

City Size Distribution has been the subject of numerous empirical investigations

Received: April 15, 2014

(C) 2014 Academic Publications, Ltd.

$\S$ Correspondence author url: www.acadpubl.eu 
by urban economists, statistical physicists and urban geographers. The interest in city size stem from two essential points. First, City Size Distribution defines the resulting landscape, and has direct consequences on the spatial distribution of cities and secondly, it is susceptible to change over time. In this context it is important to have good empirical description of City Size Distribution. The empirical facts indicate that the city growth processes vary a great deal over time and across cities. The aim of this paper is to study the vary temporal and spatial dynamics of City Size Distribution in Kerala, an Indian state for the period 1951-2001.

In section 2 a detailed account of urban scenario of Kerala is presented. Section 3 deals with the theoretical aspects of City Size Distribution models and Spatio Temporal Models. The empirical findings are given in Section 4. Conclusions based on the study are given in Section 5 .

\section{Urban Scenario in Kerala}

\subsection{Kerala and its Demographic Profile}

Kerala is one of the 28 states of India and covers an area of 38,863 square kilometers. It is the twenty-first largest state in India by area and 12th most populous state. Kerala lies in between the high Western Ghats on the east and the Arabian sea on the west, the width of the state varies from 35 kilometers to 120 kilometers. According to the geographical features the state can be divided into hills, valleys, midland plains and coastal belt. Kerala is the 9th largest contributor to Indians GDP. A demographic profile of Kerala based on 2001 census is given below:

TABLE 1(a): A Demographic Profile of Kerala and India based on 2001 Census

\begin{tabular}{|l|c|c|}
\hline Events & Kerala & India \\
\hline Total Population (in millions) & 31.84 & 1028.73 \\
\hline Decadal Population Growth (percentage) & 9.43 & 21.54 \\
\hline Population density(per.sq.km) & 819 & 324 \\
\hline Sex ratio & 1058 & 933 \\
\hline Literacy Rate (percentage) & 90.86 & 64.84 \\
\hline Percentage of Urban to Total Population & 25.97 & 27.7 \\
\hline
\end{tabular}

[Source: Census of India 2001] 


\subsection{Basic Statistics of Urban Population in kerala:}

The basic Statistics of urban and rural population according to 2001 census is given in Table $1(\mathrm{~b})$.

TABLE 1(b): Population of Kerala by sex and residence: 2001

\begin{tabular}{|c|c|c|c|c|}
\hline Kerala & Male & Female & Total Population & Sex ratio \\
\hline Urban & $40,17,332$ & $42,49,593$ & $82,66,925$ & 1058 \\
\hline Rural & $1,14,51,282$ & $121,23,167$ & $2,35,74,449$ & 1059 \\
\hline Total & $1,54,68,614$ & $1,63,72,760$ & $3,18,41,374$ & 1058 \\
\hline
\end{tabular}

The total number of urban dwellers in Kerala as per the population total of Census on India 2001 is 82,66,925. Males number 40,17,332 while Females total $42,49,593$. The total number of urban dwellers in the country is $28,53,54,954$ consisting of 15,01,35,894 males and 135,219,060 females. The percentage of urban population to total population in the country works out to $27.78 \%$ as against the ratio of $25.97 \%$ in Kerala. Kerala stands 12 th in terms of its urban population.

\section{City Size Distribution Models Rank-Size Distribution}

\subsection{Development of Models: Rank Size Distribution}

The rank size function is most widely used to investigate the relationship between city size and rank. The estimation of rank size model requires the ordering of cities form the largest down to the smallest and it relates the rank of city with its size, measured by its population. The simplest representation of this relationship is

$$
a=p r^{-} b,
$$

where a is a constant, $\mathrm{p}$ is the population of a particular city and $\mathrm{r}$ is its rank according to population size. When the exponent b equals -1 , it is referred to Zipf as the rank size rule.

In a natural logarithmic form this relationship can also be expressed as

$$
\ln p=a+b \ln r,
$$

where a is the estimate of the intercept value, which is also the estimate of the natural logarithm of the population of the largest city, and $b$ is the estimate of 
the slope coefficient of the rank size curve. On a doubly logarithmic paper, the rank size rule suggested by Zipfś appears as a straight line descending from left to right at an angle of 45 , indicating a slope of -1 .

\subsection{A Select Review of City Size Distribution Models and Spatio Temporal Models}

The first geographical analysis of City Size Distribution goes back to the beginning of the last century (Auerbach 1913), (Singer 1936) and (Zipf 1949). Zipfs law which states that the distribution of cities in a country follows a Pareto distribution has been recognized as one of those stylized facts or amazing empirical regularities in spatial economics. The pioneering empirical study (Rosen and Resnick 1980) based on rank size and primacy measures characterized the size distribution of cities in a sample of 44 countries. The study revealed that almost three fourths of the countries had Pareto exponents above unity and concluded that in most countries City Size Distribution is more even than predicted by rank-size rule. The study also examined the variations in the Pareto exponents and found that it is sensitive to city definition and sample size.

The debate focused on methodological questions related first to the effect of city definition and minimum size threshold, for including a city in the sample, on the estimates of Pareto exponent and second to the deviations from rank-size regularity. More recent advances relating to the study of City Size Distribution (Guerin-Pace 1995), (Eaton and Eckstein 1997), (Gabaix 1999a,1999b), (Soo 2005) addressed empirical evidence and econometric issues as well as the theoretical foundation of City Size Distribution, in the line of spatial theories of economic growth. The dynamics of the evolution of US City Size Distribution (Dobkins and Ioaanides 2001) based on a variety of parametric and non-parametric distributional approaches considered the convergence aspects of those dynamics.

A dynamic growth model for cities (Benguigui and Bhumenfeld Liberthal 2009) observed the changes in the value of the Pareto exponent and justified the variation of the number of entities with time. The study relating to the temporal and spatial dynamics of a regional City Size Distribution: Tamilnadu (1951-2001). (Subbarayan, Kumar and Christopher Amalraj 2011) revealed that the Pareto exponent rises over time, indicating an increase in the size of the largest city without a threshold population. It has also been observed that lower ranking towns away from the central city are not found to have grown at a faster rate.

It has been established that the rank size rule is not only satisfied for Ger- 
manys national urban hierarchy, but also for the City Size Distribution in a single German regions (Giessen and Suedekum 2011). This important aspect has motivated the authors to study the Spatio temporal dynamics of a region viz., Kerala in India which has different geographical characteristics from that of other states with a threshold population using expansion methodology.

\subsection{Expansion Method}

The expansion method (Casetti 1972, 1995), (Casetti and Krackover 1990) and (Fan 1988) originates from an analysis of thought processes that lead to the construction of any mathematical models of realities. The expansion method encompasses a technique for constructing mathematical models and rationales concerning its use. In a nutshell, it involves in widening the scope of a simple initial model by redefining some or all its parameters into functions of expansion variables. The terminal model thus produces includes both the initial model and a specification of its contextual variation.

In the rank- size applications of the expansion method the parameters of a rank size model have been expanded into functions of time. In the classical rank-size models the natural logarithm of citys population is linearly relater to natural logarithm of its rank. The time expansions of the parameters of this type of models have been used to investigate the differential growth of urban centers. The expansion method is well suited to modeling complex spatial dynamics because it allows the linking of geographical entities such as countries or regions to dynamics that vary across space and time.

\subsection{Spatio Temporal Models}

The expansion method introduces a procedure through which a terminal model is generated from an initial model by making the parameters of the latter functions of other relevant variables. An expansion in a specific dimension, such as time or distance, would then capture the quantitative change of initial parameters along that dimension. To investigate changes in an urban system through time, equation (3.1.2) is defined as the initial model. Both the parameter a, which is the estimate of the natural logarithm of the largest citys population, and the slope coefficient b can vary through time, and they can be redefined by the following expansion equations:

$$
\begin{gathered}
a=a_{0}+a_{1} t \\
b=b_{0}+b_{1} t
\end{gathered}
$$




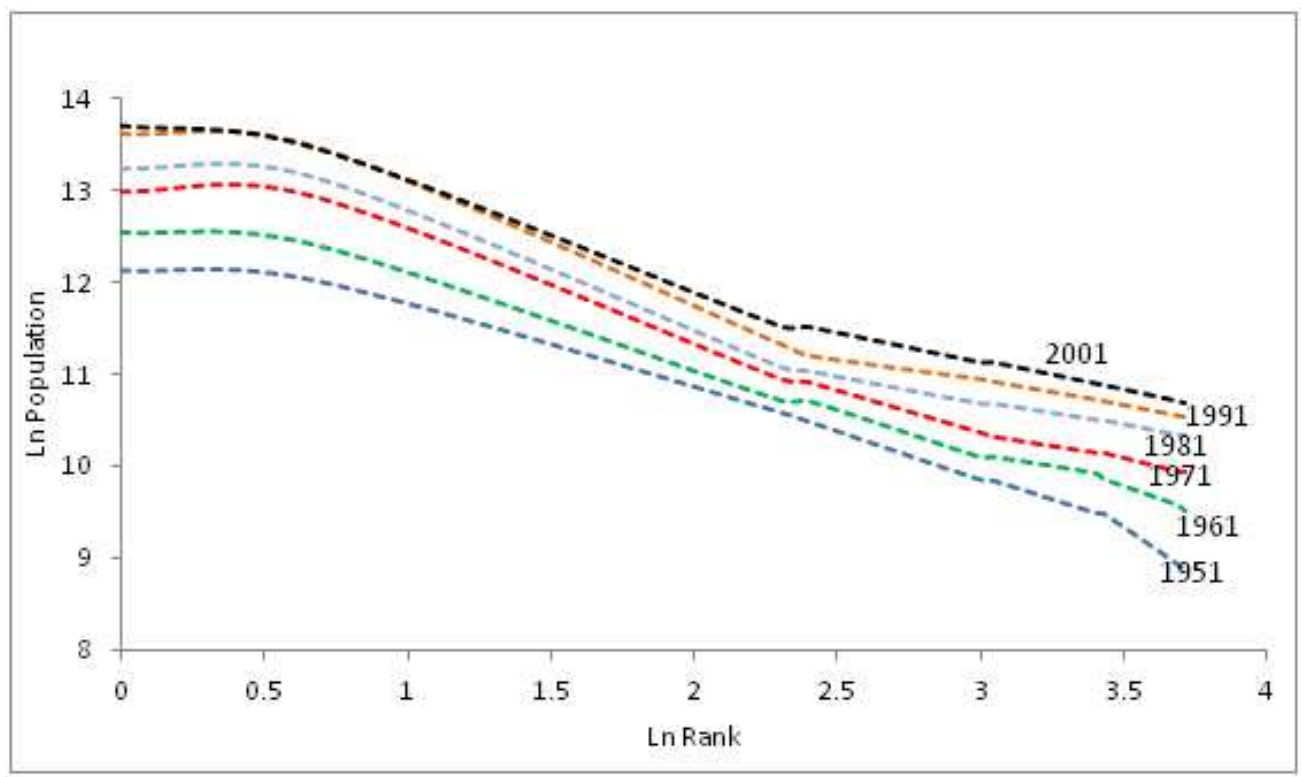

Figure 1: Rank Size Curves For Fixed List - 1951-2001

where $\mathrm{t}$ is time. By replacing the parameters in equation (3.1.2) by the righthand sides of equations (3.5.1) and (3.5.2) the following terminal model is obtained:

$$
\ln p+a_{0} t+a_{1} t+b_{0} \ln r+b_{1} t \ln r
$$

It is noted that the signs of the estimates for the expansion parameters $a_{1}$ and $b_{1}$ show the direction of the linear trend of a and $\mathrm{b}$ over time. Significance tests for the two expansion parameters will also tell whether the change of a and $\mathrm{b}$ over time is the result of chance. If $a_{1}$ is significant and positive, the estimated intercept value has increased in time, indicating that the largest city in the urban system has increased in size. If $b_{1}$ is also significant and positive, the rank-size curve has become less steep in time, because higher-ranking cities have been growing at a slower rate than lower-ranking cities, as the result of a trend toward population deconcentration. However, if $b_{1}$ is negative and significant, the curve has become steeper in time, indicating a trend toward population concentration.

To incorporate this spatial dimension into our analysis, the distance from the central city of the state is used. Urban policy is to promote spatial equity in population distribution through encouraging growth of inland towns/cities. For successful implementation of this policy we would expect the trend toward 


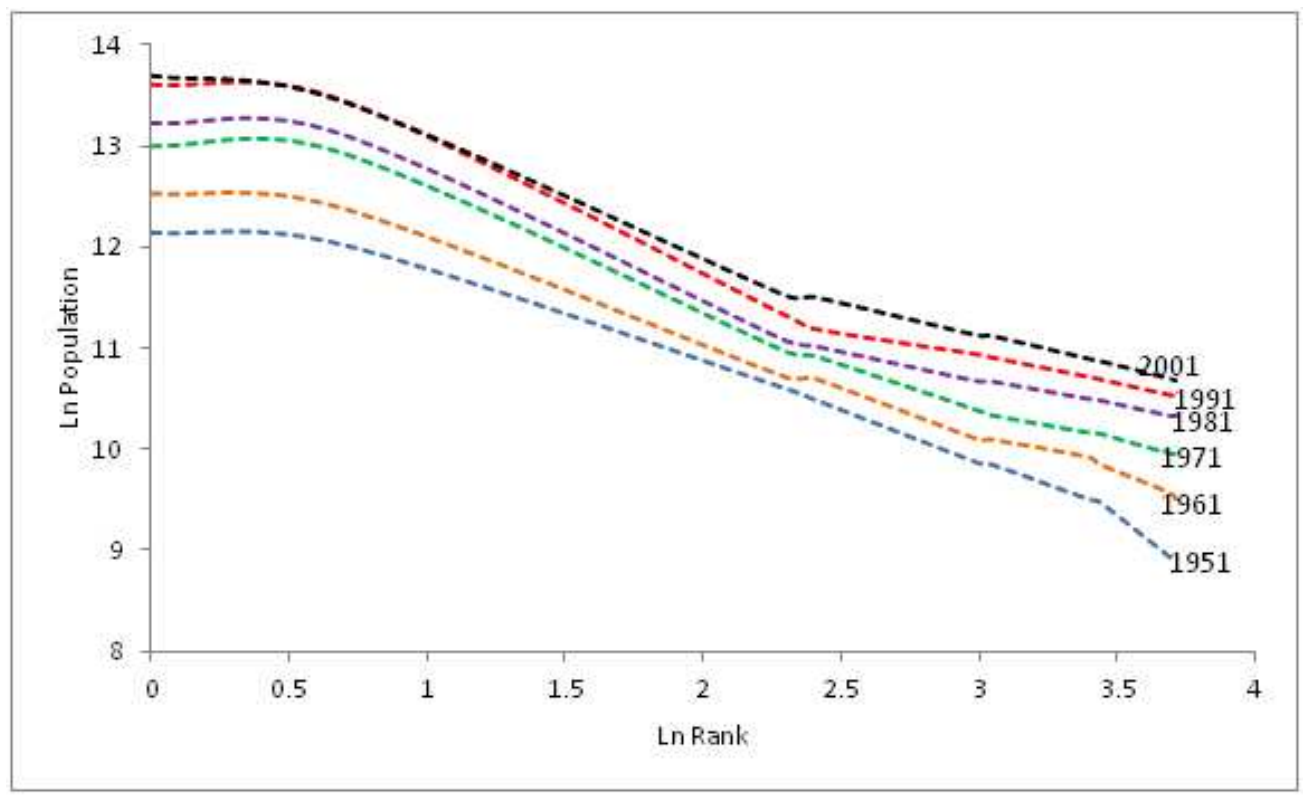

Figure 2: Rank Size Curves For Top List - 1951-2001

population deconcentration (with the rank size curve becoming less steep) to be more significant in the interior of the country.

The parameter $b_{1}$ in equation (3.5.3) can be defined as a function of distance:

$$
b_{1}=b_{10}+b_{11} d
$$

whered is the shortest straight-line distance from the central city of the state. Substituting the right-hand side of equation (3.4.4) into equation (3.4.3) generates another terminal model, which takes into account both the temporal and spatial trends of the b-coefficient:

$$
\ln p=a_{0}+a_{1} t+b_{0} \ln r+b_{10} t \ln r+b_{11} d t \ln r
$$

The direction and significance tests for the parameter $b_{11}$ will show if the temporal drift of the b-coefficient (captured by $b_{1}$ ) varies over distance. If spatial decentralization is successful, is expected to be both positive and significant, suggesting that the degree of population deconcentration over time is greater as one moves away from the center to the other parts of the state. 


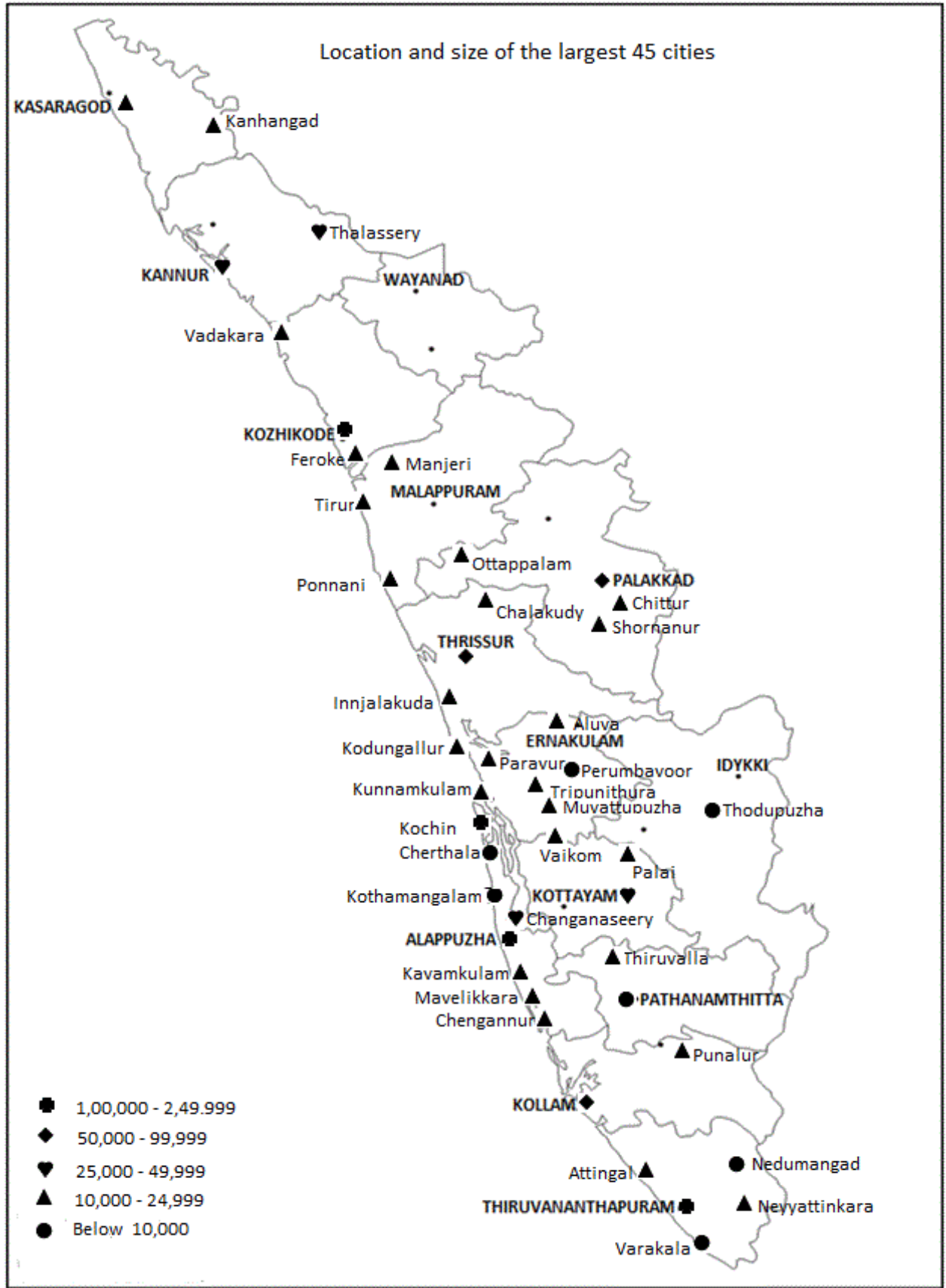

Figure 3: Location and size of the 45 largest cities in 1951 


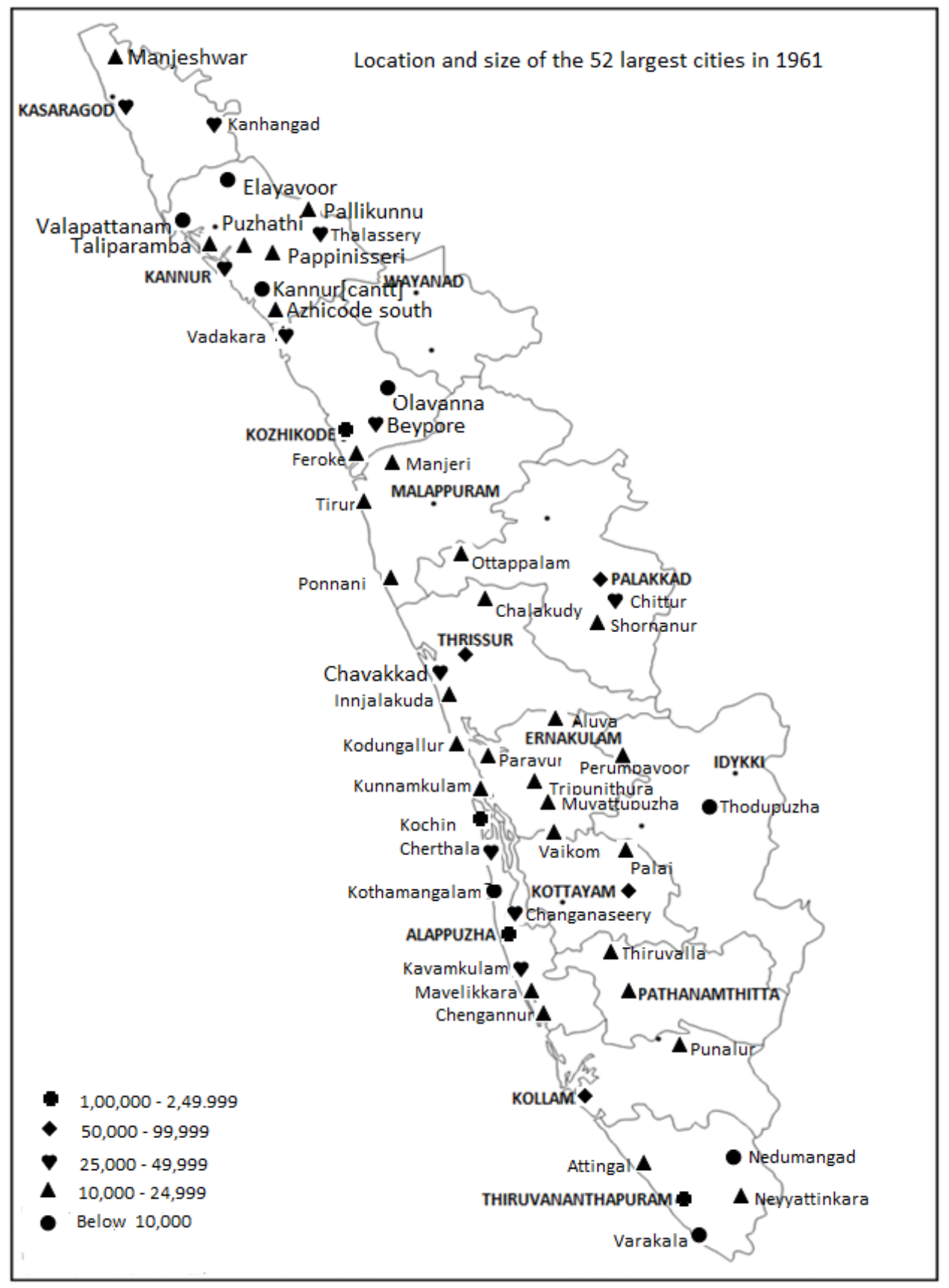

Figure 4: Location and size of the 52 largest cities in 1961 


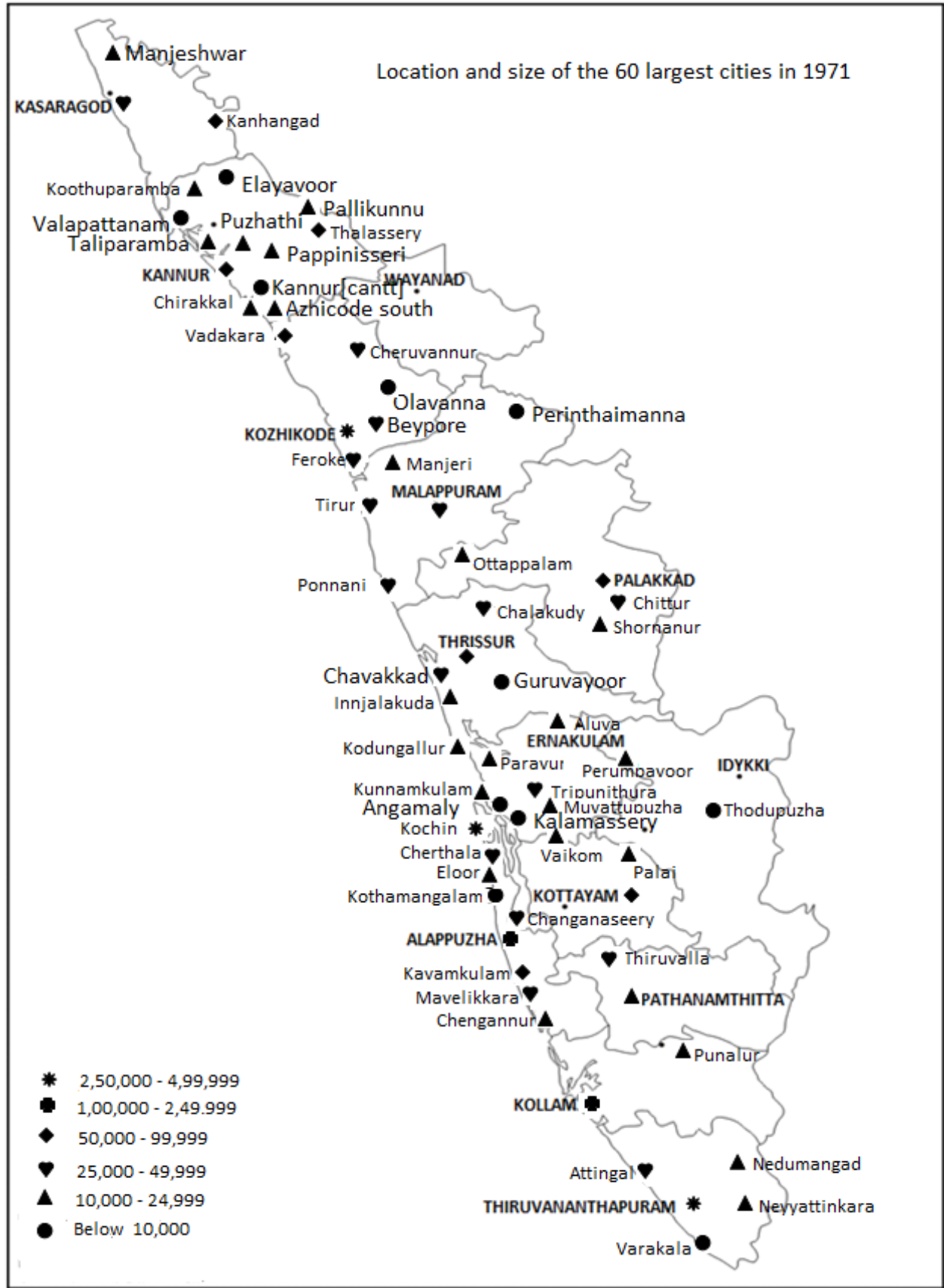

Figure 5: Location and size of the 60 largest cities in 1971 


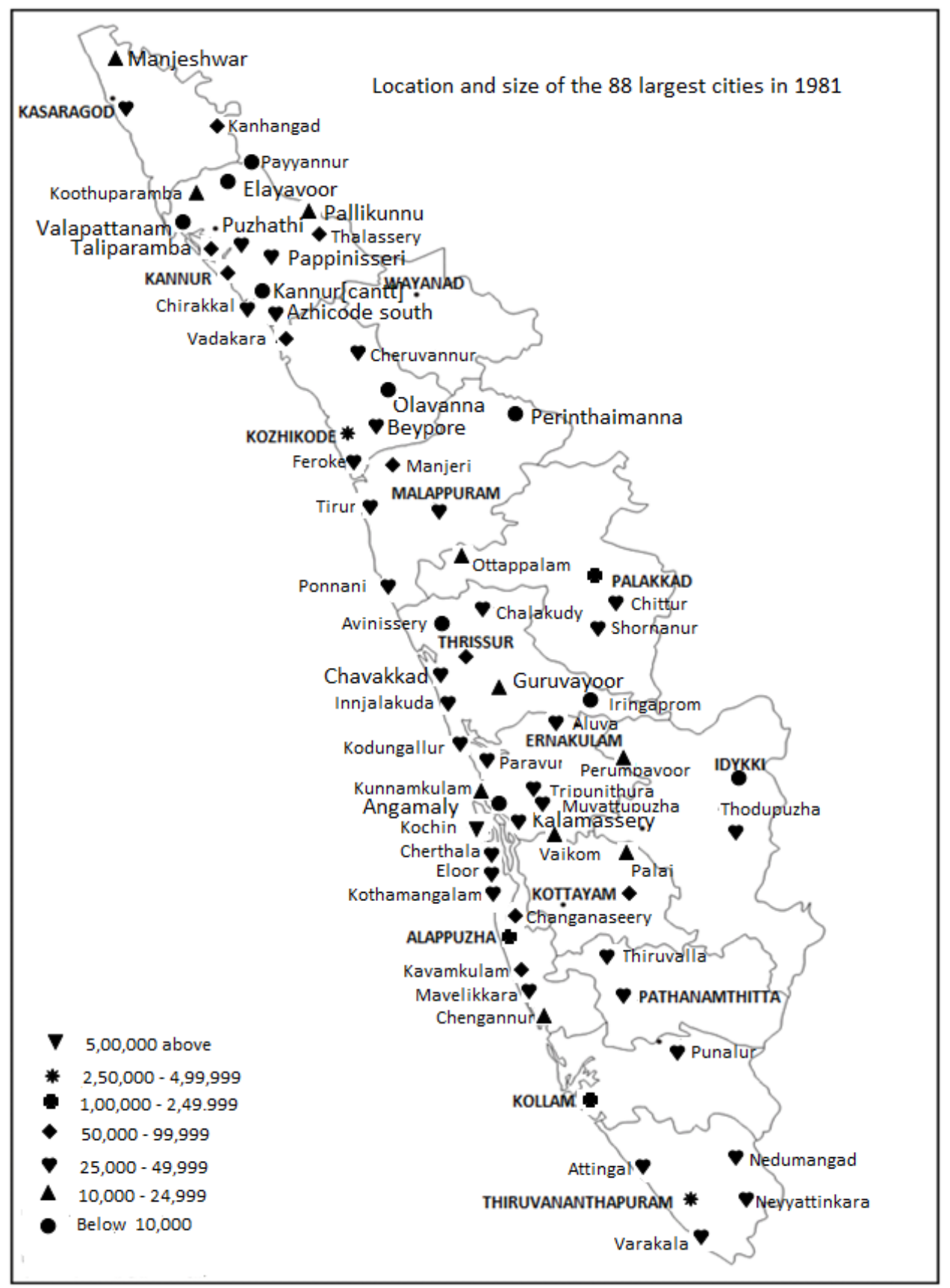

Figure 6: Location and size of the 88 largest cities in 1981 


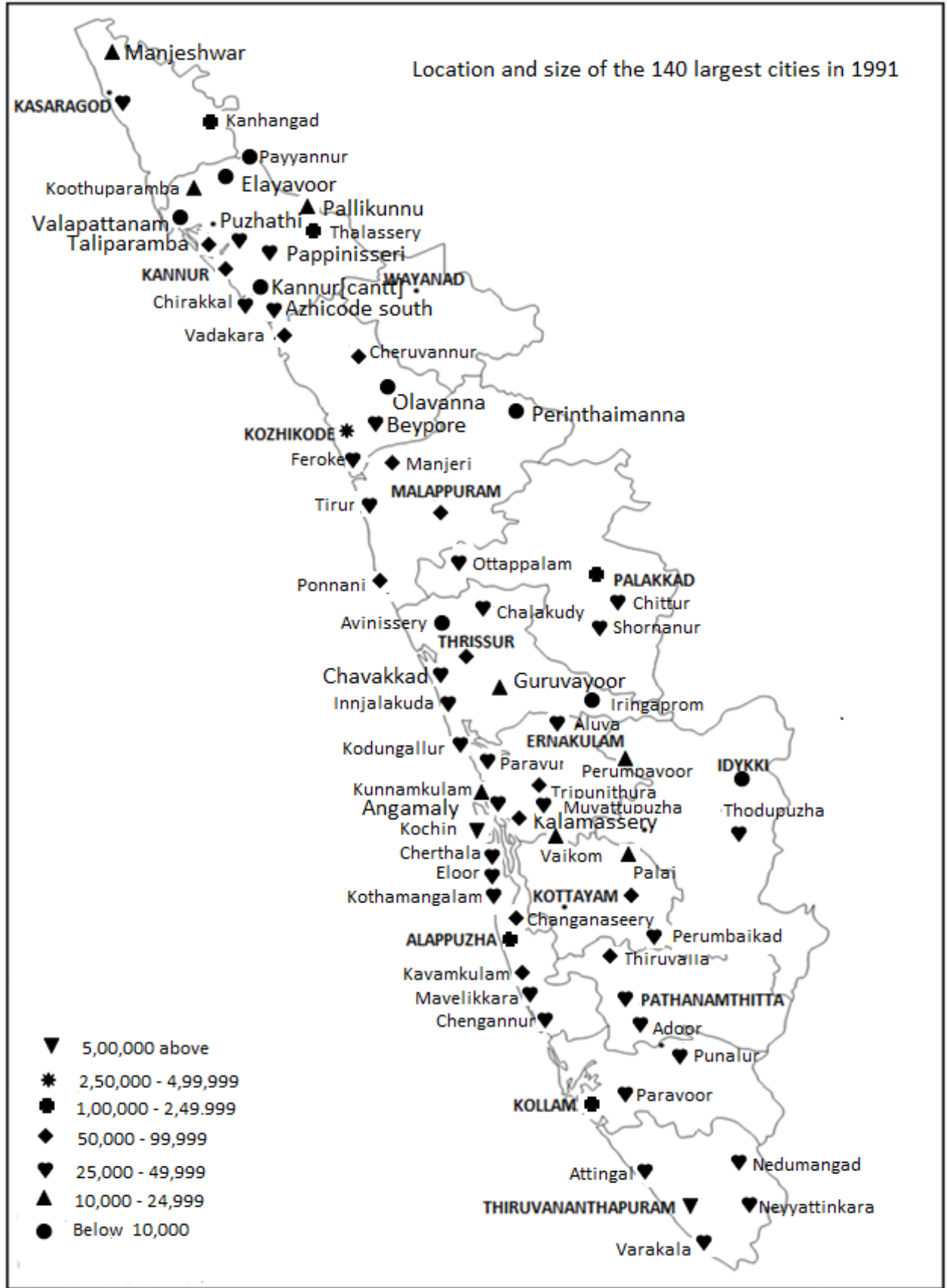

Figure 7: Location and size of the 140 largest cities in 1991 


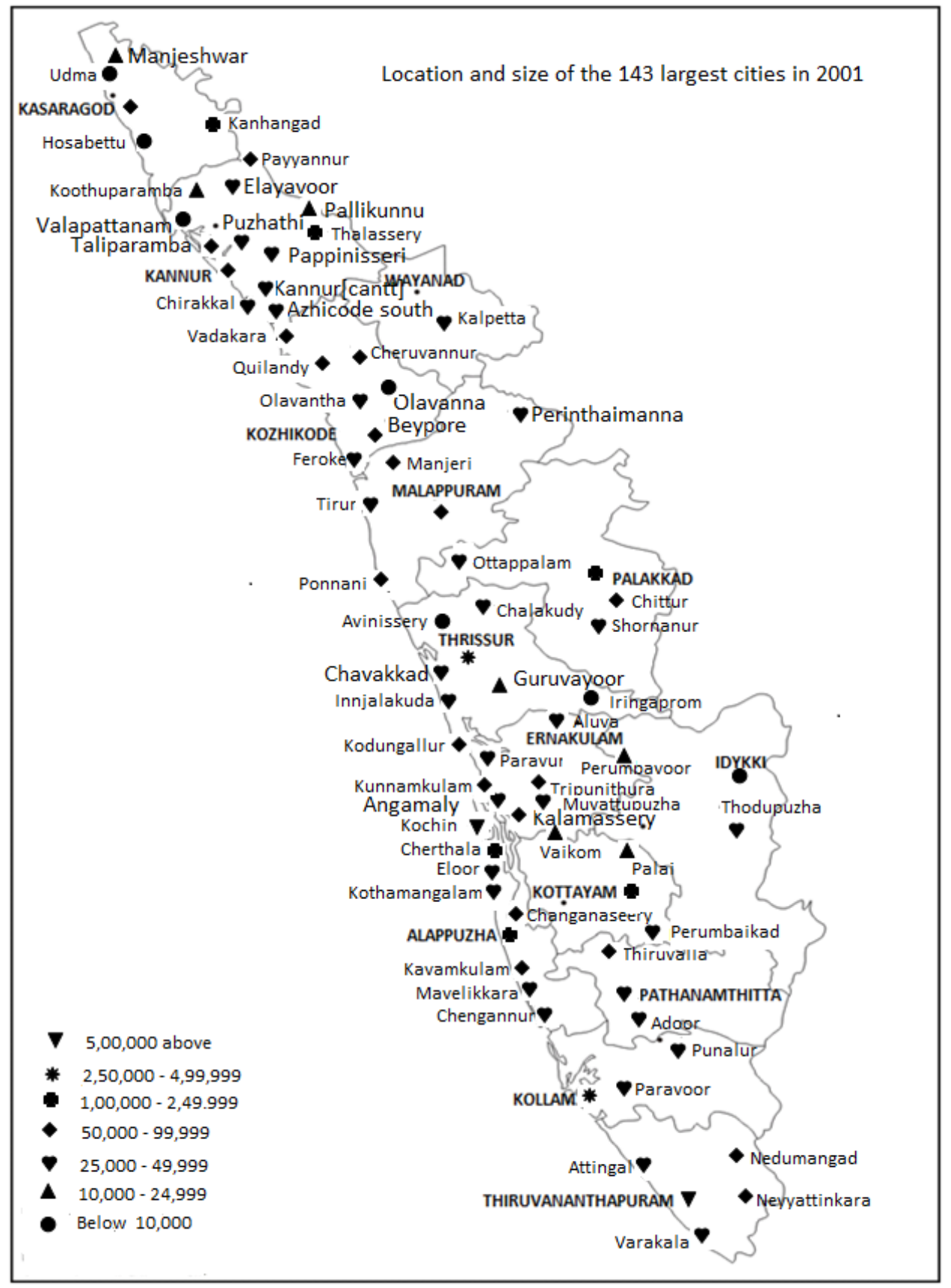

Figure 8: Location and size of the 143 largest cities in 2001 


\section{The Empirical Analysis}

\subsection{Urban Size Class under Indian Census}

India has very rich source of information for urban studies. The census volumes, both at the National and state and district levels, provide a mine of information for rural and urban places for period of 100 years. It is also main source of information for temporal studies focusing in the recent past. The census periods covered are: 1951, 1961, 1971, 1981, 1991 and 2001.

Urban Population by size classification is based on the following

\begin{tabular}{|c|c|}
\hline Class & Population \\
\hline I & $>1,00,000$ \\
\hline II & $50,000-1,00,000$ \\
\hline III & $20,000-50,000$ \\
\hline IV & $10,000-20,000$ \\
\hline V & $5,000-10,000$ \\
\hline VI & $<5,000$ \\
\hline
\end{tabular}

TABLE 2: Kerala: City size distribution (No. of cities/towns).

\begin{tabular}{|c|c|c|c|c|c|c|c|}
\hline $\begin{array}{c}\text { Census } \\
\text { Year }\end{array}$ & $\begin{array}{c}>1,00,000 \\
>1,00,000\end{array}$ & $\begin{array}{c}50,000- \\
1,00,000\end{array}$ & $\begin{array}{c}20,000- \\
50,000\end{array}$ & $\begin{array}{c}10,000- \\
20,000\end{array}$ & $\begin{array}{c}5,000- \\
10,000\end{array}$ & $\begin{array}{c}<5,000 \\
<5,000\end{array}$ & $\begin{array}{c}\text { Total } \\
\text { Total }\end{array}$ \\
\hline 1951 & 4 & 3 & 10 & 21 & 6 & 1 & 45 \\
\hline 1961 & 4 & 4 & 22 & 17 & 4 & 1 & 52 \\
\hline 1971 & 5 & 8 & 32 & 11 & 3 & 1 & 60 \\
\hline 1981 & 6 & 8 & 55 & 14 & 4 & 1 & 88 \\
\hline 1991 & 9 & 17 & 69 & 34 & 10 & 1 & 140 \\
\hline 2001 & 10 & 24 & 72 & 37 & 15 & 1 & 159 \\
\hline
\end{tabular}

\subsection{Fixed list and Top list}

Appendix A lists the first set of data, consisting of population and rank for 143 cities/towns and these 143 cities/towns had a population of 10,000 or more in 2001. Since the towns in the data set are fixed, their relative growth can be computed and compared. However, because of the long time span covered in this study, some of these cities were relatively small in size and were not within the top portion of the urban system in the early of the period studied. To give a more complete picture of the changes in the urban system, a second data set, consisting of 143 cities/towns largest cities at each of six points in time, is added (Appendix B). The fixed list is expected to complement the top list. 


\subsection{Regression analysis for the data in the fixed list and top list}

The results of regression analysis for estimating the rank-size function according to equation (3.1.2), for the fixed list and top list are given in the following Table $3(\mathrm{a})$ and 3(b). The standard error values are given beneath the intercept and slop coefficients.

TABLE 3(a): Estimates for Rank-size function for Fixed list (KERALA

$$
\geq 10,000)
$$

\begin{tabular}{|c|c|c|c|c|}
\hline Census Year & $\mathrm{a}$ & $\mathrm{b}$ & $\mathrm{R}^{2}$ & Sig-Level \\
\hline 1951 & $12.822(0.125)$ & $1.015(0.042)$ & 0.932 & 0.0001 \\
\hline 1961 & $12.989(0.081)$ & $0.946(0.026)$ & 0.965 & 0.0001 \\
\hline 1971 & $13.233(0.089)$ & $0.926(0.028)$ & 0.953 & 0.0001 \\
\hline 1981 & $13.201(0.090)$ & $0.806(0.025)$ & 0.926 & 0.0001 \\
\hline 1991 & $13.622(0.064)$ & $0.834(0.016)$ & 0.955 & 0.0001 \\
\hline 2001 & $13.778(0.053)$ & $0.839(0.013)$ & 0.967 & 0.0001 \\
\hline
\end{tabular}

TABLE 3(b): Estimates for Rank-size function for Top list (KERALA $\geq$ $10,000)$

\begin{tabular}{|c|c|c|c|c|}
\hline Census Year & $\mathrm{a}$ & $\mathrm{b}$ & $\mathrm{R}^{2}$ & Sig-Level \\
\hline 1951 & $12.822(0.125)$ & $1.015(0.042)$ & 0.932 & 0.0001 \\
\hline 1961 & $13.089(0.122)$ & $0.992(0.039)$ & 0.928 & 0.0001 \\
\hline 1971 & $13.304(0.108)$ & $0.957(0.033)$ & 0.935 & 0.0001 \\
\hline 1981 & $13.286(0.110)$ & $0.837(0.030)$ & 0.900 & 0.0001 \\
\hline 1991 & $13.775(0.087)$ & $0.884(0.021)$ & 0.926 & 0.0001 \\
\hline 2001 & $13.778(0.053)$ & $0.839(0.013)$ & 0.967 & 0.0001 \\
\hline
\end{tabular}

The standard error values are given beneath the intercept and slop coefficients.

(i) In both the cases (fixed list and top list) the estimate for the intercept a rises upto 1971 and there is a marginal decrease in 1981. After 1981 till 2001 there is sharp increase in the estimate and indicates an increase in size of the largest city as predicted by the model [Figure 1 and Figure 2].

(ii) Changes in $\mathrm{b}$ estimate for the period of study suggest that the size distribution of cities shows a decreasing and increasing pattern and indicating a more even and less even distribution of city/town population. 


\subsection{Rank Size Function Expanded in Time}

The Tables 4(a) and 4(b) contains estimate for the rank-size function expanded in time for fixed and top list for the period of study. Figure 1 and Figure 2 shows the rank-size function expanded in time for fixed and top list for the period of study.

TABLE 4(a): Estimates for Rank-Size function expanded in time for fixed list

\begin{tabular}{|c|c|c|c|}
\hline Parameter & Estimates & S.E & Sig. Level \\
\hline$a_{0}$ & 12.633 & $(0.067)$ & 0.0001 \\
\hline$a_{1}$ & 0.241 & $(0.020)$ & 0.0001 \\
\hline$b_{0}$ & -0.921 & $(0.021)$ & 0.0001 \\
\hline$b_{1}$ & 0.018 & $(0.006)$ & 0.0020 \\
\hline
\end{tabular}

TABLE 4(b): Estimates for Rank-Size function expanded in time for Top list

\begin{tabular}{|c|c|c|c|}
\hline Parameter & Estimates & S.E & Sig. Level \\
\hline$a_{0}$ & 12.732 & $(0.078)$ & 0.0001 \\
\hline$a_{1}$ & 0.231 & $(0.023)$ & 0.0001 \\
\hline$b_{0}$ & -0.965 & $(0.024)$ & 0.0001 \\
\hline$b_{1}$ & 0.024 & $(0.007)$ & 0.0001 \\
\hline
\end{tabular}

In both the list (fixed and top) the parameter $b_{1}$ is positive and significant implying that the changes in b-coefficient over time are significant and this indicates that there is evidence for trends in population deconcentration.

\subsection{5 Location and Size of 143 cities/towns for Studying Inequality}

A general principle in Kerala policy is to promote spatial equity by limiting the growth of biggest cities and encouraging the growth of smaller and medium type of cities/towns in a balanced manner throughout the state for development of cities/towns in all sectors of the economy.

(i) It may be noted that we have considered Thrissur as the centre of Kerala and computed the shortest straight line distance (d) in the equation (3.5.5) of the 143 cities/towns from Thrissur.

(ii) The location and size of the 143 largest cities/towns for the period 1951-2001 at 6 points of time are shown in Figure 3 to Figure 8. 


\subsection{Rank Size Function Expanded in Time and Distance}

The estimate for the rank size function expanded in time and distance for fixed and top list for the period of study are given in the Tables 5(a) and 5(b).

TABLE 5(a):

Estimates for Rank-size function expanded in time and distance for fixed list, $1951-2001$

\begin{tabular}{|c|c|c|c|}
\hline Parameter & Estimates & S.E & Sig-Level \\
\hline$a_{0}$ & 12.633 & $(0.067)$ & 0.0001 \\
\hline$a_{1}$ & 0.241 & $(0.020)$ & 0.0001 \\
\hline$b_{0}$ & -0.921 & $(0.021)$ & 0.0001 \\
\hline$b_{10}$ & 0.016 & $(0.006)$ & 0.0050 \\
\hline$b_{11}$ & $-9.103 \mathrm{E}-6$ & $(0.000)$ & 0.2040 \\
\hline
\end{tabular}

$$
\mathrm{R}^{2}=0.944, \mathrm{~F}=2129.667, \text { Sig.Level }=0.0001, \mathrm{DF}=4: 504
$$

TABLE 5(b):

Estimates for Rank-size function expanded in time and distance for Top list, 1951-2001

\begin{tabular}{|c|c|c|c|}
\hline Parameter & Estimates & S.E & Sig-Level \\
\hline$a_{0}$ & 12.732 & $(0.078)$ & 0.0001 \\
\hline$a_{1}$ & 0.231 & $(0.023)$ & 0.0001 \\
\hline$b_{0}$ & -0.965 & $(0.024)$ & 0.0001 \\
\hline$b_{10}$ & 0.022 & $(0.007)$ & 0.0010 \\
\hline$b_{11}$ & $-1.151 \mathrm{E}-5$ & $(0.000)$ & 0.1900 \\
\hline
\end{tabular}

$$
\mathrm{R}^{2}=0.930, \mathrm{~F}=1733.469, \text { Sig.Level }=0.0001, \mathrm{DF}=4: 523
$$

The parameter $b_{11}$ in both the lists is not significant. This clearly indicates that any trend towards population deconcentration in respect of 143 cities/towns listed in the fixed and top list is not affected by distance from the central city of Kerala. In other words, lower ranking towns away from the central city are not found to have grown at a faster rate. This confirms that the distance from the central city is not a significant factor in any trend towards population deconcentration. 


\section{Conclusion}

A comprehensive understanding of urban growth process is essential for characterizing and analyzing the City Size Distribution across spatial and temporal scales. The basic tool used in this approach is the rank size distribution. By using expansion methodology the parameters of a rank size model have been expanded into functions of time and distance. The expansion methodology is thus well suited to modeling complex spatial dynamics.

The important conclusions based on the findings are given below:

(i) First, In both cases (fixed list and top list) the size distribution of cities shows an decreasing and increasing pattern and indicating a more even or less even distribution of city/town population.

(ii) Secondly, the result reveals that there is evidence for trends in population deconcentration.

(iii) Thirdly, the lower ranking towns away from the central city and not found to have grown at a faster rate.

(iv) Finally, the frame work proposed and utilized in the analysis can be used to evaluate regional and national urban policies.

\section{References}

[1] Auerbach F, Das Gesetz. 1913. Das Geset der Belvolkerungskoncentration. Peterman Geogr Mitt, 59, 74-76.

[2] Singer HW. 1936. The courbe des population: a parallel to Paretos law Economic Journal, 46, 254-263.

[3] Zipf GK. 1949. Human Behavior and the principle of Lease Effort, Reading, MA: Addison Wesley.

[4] Rosen KT, Resnick M. 1980. The size Distribution Cities, Journal of Urban Economics, 8, 165-186.

[5] Guerin-Pace, 1995. Rank Size Distribution and the Processor of Urban Growth, Urban Studies, 32, 551-562.

[6] Eaton J, Eckstein Z. 1997. Cities and Growth: Theory and evidence from France and Japan, Regional Science and Urban Economics, 27, 443-474. 
[7] Gabaix X. 1999a. Zipfs law and the growth of cities, American Economic Review, 89, 129 -132.

[8] Gabaix X. 1999b. Zipfs law and the growth of cities, An Explanation, Quarterly Journal of Economics, 114, 734-767.

[9] Soo KT. 2005. Zipfs law for Cities: A Cross Country investigation, Regional Science and Urban Economics, 35, 239-263.

[10] Dobkins LH, Ioannides YM. 2001. Spatial Interactions among US Cities:1900 -1990, Regional Science and Urban Economics, 31, 701-732.

[11] Bengugui L, Blumenfeld Liberthal. 2009. The temporal evolution of the city size distribution, Physica A, 388, 1187-95.

[12] Subbarayan A, Kumar G, Christopher Amalraj V. 2011. The temporal and spatial dynamics of regional city-size distribution: Tamilnadu (1951-2001), International Journal of Agricultural and Statistical Sciences, 7, 535-554.

[13] Giesen K, Suedekum J. 2011. Zipfs law for cities in the regions and the country, Journal of Economic Geography, 11, 667-686.

[14] Casetti E. 1972 Generating models by the expansion method: Applications to geographical research, Geographical Analysis, 4, 81-91.

[15] Casetti E. 1995. Spatial Mathematical modeling and regional science, Papers in Regional Science, 74, 3-11.

[16] Casetti E, Krakover. 1990. Spatio-temporal dynamics of the U.S Population: Estimates and extrapolations, Socio-Spatial Dynamics, 1, 139-159.

[17] Fan CC. 1988. The temporal and spatial dynamics of city-size distribution in China, Population Research and Policy Review, 7, 123-157. 
